Check for updates

Cite this: Chem. Commun., 2020, 56,6340

Received 9th April 2020

Accepted 28th April 2020

DOI: $10.1039 / \mathrm{d} 0 \mathrm{cc} 02509 \mathrm{~g}$

rsc.li/chemcomm

\section{Regioselective biocatalytic self-sufficient Tishchenko-type reaction via formal intramolecular hydride transfer $\dagger$}

\author{
Erika Tassano, (D) a Kemal Merusic, (D) a Isa Buljubasic, ${ }^{a}$ Olivia Laggner, ${ }^{a}$ \\ Tamara Reiter, ${ }^{a}$ Andreas Vogel ${ }^{b}$ and Mélanie Hall (D *a
}

\begin{abstract}
A self-sufficient nicotinamide-dependent intramolecular bio-Tishchenkotype reaction was developed. The reaction is catalyzed by alcohol dehydrogenases and proceeds through formal intramolecular hydride transfer on dialdehydes to deliver lactones. Regioselectivity on [1,1'-biphenyl]-2,2' -dicarbaldehyde substrates could be controlled via the electronic properties of the substituents. Preparative scale synthesis provided access to substituted dibenzo[c,e]oxepin- $5(7 H)$-ones.
\end{abstract}

The Claisen-Tishchenko reaction is a disproportionation reaction that leads to the formation of esters through dimerization of aldehydes. ${ }^{1}$ Due to the variety of protocols available, it is a synthetically relevant transformation ${ }^{2}$ and one of the major approaches for the bulk production of ethyl acetate. ${ }^{3}$ The Lewis acid promoted Tishchenko reaction involves a reduction-oxidation sequence, typically in the presence of aluminium alkoxides. ${ }^{2}$ The intramolecular reaction transforms dialdehydes to corresponding lactones, and several catalysts - mostly transition metal and rare earth compounds - have been explored with varying efficiency. ${ }^{4-6}$ 1,4- and 1,5-dialdehydes are preferred since formation of $\gamma$ - and $\delta$-lactones, respectively, is thermodynamically favored. The reaction proceeds through hydrogen or hydride borrowing, ${ }^{7,8}$ whereby one aldehyde is first reduced to the alcohol, which combines with the second aldehyde group to yield a hemiacetal intermediate that gets oxidized. This redox-neutral reaction can be applied to ketoaldehydes. ${ }^{5,8,9}$ To the best of our knowledge, biocatalytic equivalents have not been disclosed. The case of photoheterotrophic cultures of the algae Euglena gracilis Z, which were reported to promote the conversion of $o$-phthalaldehyde to phthalide, ${ }^{10}$ raised our interest, as it indicates that a biocatalytic approach to the intramolecular Tishchenko reaction may be possible. No clear mechanistic pathway was identified, but elusive formation of 2-(hydroxymethyl)-benzoic acid as intermediate was suggested.

\footnotetext{
${ }^{a}$ Department of Chemistry, University of Graz, Heinrichstrasse 28, $8010 \mathrm{Graz}$, Austria.E-mail:melanie.hall@uni-graz.at

${ }^{b}$ c-LEcta GmbH, Perlickstrasse 5, 04103 Leipzig, Germany

$\dagger$ Electronic supplementary information (ESI) available. See DOI: 10.1039/d0cc02509g
}

Recently, we established a biocatalytic variant of the (intermolecular) Cannizzaro reaction, which could be further developed into a parallel interconnected dynamic asymmetric disproportionation of $\alpha$-substituted aldehydes. The system relies on the concurrent oxidative and reductive activity of nicotinamide-dependent alcohol dehydrogenases (ADHs) to perform the dismutation of aldehydes with high enantioselectivity in a redox-neutral fashion. ${ }^{11,12}$ The latter feature renders the system appealing from a sustainability point of view, since only catalytic amounts of cofactor are necessary, in addition to the biocatalyst. Since two products are generated, an additional purification step is necessary, or alternatively, convergent processes toward a single product must be designed. In this regard, the intramolecular Tishchenko reaction is highly attractive since only one product may be formed.

Pioneering work by Jones and coworkers showed that the enzymatic double oxidation of 1,4- and 1,5-diols catalyzed by NAD-dependent horse liver alcohol dehydrogenase (HLADH) proceeds through formation of the hydroxyaldehyde that spontaneously undergoes cyclization to the corresponding lactol, which gets further oxidized to the lactone product; overall two equivalents of $\mathrm{NAD}^{+}$are necessary. ${ }^{13,14}$ The HLADH-catalyzed transformation of diols to lactones was subsequently employed in studies focusing on nicotinamide cofactor regeneration strategies. ${ }^{15}$ This biotransformation recently witnessed a 'renaissance ${ }^{, 16}$ and has been applied to various synthetic and cofactor recycling protocols. ${ }^{17}$ Biocatalytic systems based on laccase-catalyzed oxidation of diols to lactones also exist. ${ }^{18}$

Aiming at high hydride-economy in biosynthetic protocols, we evaluated the feasibility of a nicotinamide-dependent selfsufficient biocatalytic intramolecular Tishchenko-type reaction catalyzed by a single ADH in presence of catalytic amounts of cofactor, which would not rely on the presence of a co-substrate nor generate any by-product (Scheme 1). Such minimalistic in vitro cofactor-dependent biocatalytic systems yielding a single product are rare, ${ }^{16}$ and so far limited to racemization of enantiomerically pure molecules $^{19}$ and redox isomerization reaction. ${ }^{20}$

The catalytic activity of several ADHs with dialdehydes toward formation of lactone products was first investigated 


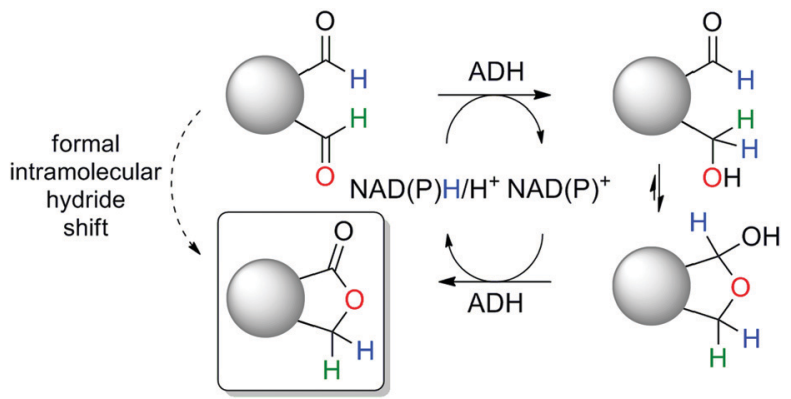

Scheme 1 Biocatalytic intramolecular Tishchenko-like reaction catalyzed by alcohol dehydrogenase (ADH).

on $o$-phthalaldehyde (1a) as model substrate, employing a collection of NADH-dependent ADHs (Scheme 2). ${ }^{21}$ All reactions were run in presence of acetonitrile as co-solvent in a concentration typically well tolerated by ADHs (5 vol\%). ${ }^{16,17,26 b}$ Catalytic amounts of cofactor $(0.05 \mathrm{eq}$.) were employed on $10 \mathrm{mM}$ substrate and the reaction was run at $\mathrm{pH} 7$ and $30{ }^{\circ} \mathrm{C}$. Phthalide (1b) was obtained as sole product with several enzymes in up to $74 \%$ conversion, indicating internal recycling of the cofactor (up to $\sim 15$ turnovers, see ESI, $\uparrow$ Table S1) and effective formal intramolecular 1,4-hydride shift. Accumulation of the lactol intermediate could be detected only in a few cases (see ESI, $\dagger$ Fig. S1). This confirms that the reaction proceeds through a reduction-oxidation sequence, with formation of the hydroxyaldehyde first - leading to the lactol ${ }^{13}$ - followed by its oxidation to the lactone (Scheme 1). No product was formed in absence of enzyme. The enzymatic reaction proceeded fast on 1a (max. conversion reached after $\sim 120$ min with ADH-172, see ESI, $\dagger$ Fig. S2) and additional experiments conducted with $\mathrm{ADH}-132$ seem to indicate that conversion was not limited by the activity of the enzyme but rather by the substrate and/or cofactor availability (see ESI, $\dagger$ Table S2).

The scope of the reaction was enlarged by testing structurally related 2a and 3a (see ESI, $\dagger$ Table S3). Since these dialdehydes are unsymmetrical, the reaction can produce two regioisomers $2 / 3 \mathbf{b}$ and $2 / 3 \mathbf{c}$ (Scheme 2), depending on the regioselectivity of the biocatalyst. In general, 2-(3-oxopropyl)benzaldehyde (3a) was better accepted by most ADHs, and conversion reached up to 70\% with ADH-110 (entry 3, Table S3, ESI $\dagger$ ). In contrast, conversion of 2-(2-oxoethyl)benzaldehyde (2a) was limited to max. 27\% with ADH-171 (entry 11, Table S3, ESI $\dagger$ ). The regiopreference was strongly enzyme-dependent. With $3 \mathbf{a}$, in all cases except with ADH-170, 4,5-dihydrobenzo[c]oxepin-1(3H)-one (3b) was the major product. Noteworthy, ADH-114 displayed exquisite regioselectivity (3b/3c in $>99: 1$ ratio), along with very good conversion level, which was at the highest on $20 \mathrm{mM} 3 \mathrm{a}$ (added in two aliquots over $3 \mathrm{~h}, 67 \%$ conversion, entry 6, Table S3, ESI $\dagger$ ). Complementary biocatalytic approach to such lactones using Baeyer-Villiger monooxygenase could not produce this regioisomer. ${ }^{22}$ On $\mathbf{2 a}$, the regioselectivity pattern was mixed, with enzymes displaying moderate conversion level and preference for isochroman-3-one (2c), or low conversion level along with preference for isochroman-1-one (2b). With ADH-110, 111 and 132, which did not produce any lactones $2 \mathbf{b}-2 \mathbf{c}$ from $2 \mathbf{a}$, traces of lactol were detected, indicating that the oxidation step in these cases was not taking place. Since the reduced cofactor is used in catalytic amounts, the overall reaction relies on the regeneration of NADH through lactol oxidation. In its absence, the system reaches a dead-end and the substrate does not get converted beyond the availability of the cofactor, here $0.5 \mathrm{mM}$. Other competing phenomena with $\mathbf{2 a}$, likely initiated by the hydration of one aldehyde group, ${ }^{11}$ were observed but not studied further (see ESI, $\dagger$ Fig. S3 and Scheme S1). A time study performed on 3a with ADH-114 highlighted that the reaction was much slower compared to the biotransformation of 1a (see ESI, $\dagger$ Fig. S4). This reaction was performed on $200 \mathrm{mg}$ scale. Under the reaction conditions reported in Table S3 (ESI $\dagger$ ) (entry 6), $105 \mathrm{mg}$ of $\mathbf{3 b}$ could be obtained after purification by flash chromatography (53\% isolated yield, see ESI, $\dagger$ Fig. S5).

In addition to commercial ADHs, we turned our attention to a variant of NADPH-dependent ADH from Lactobacillus kefir ( $\left(\mathrm{Lk}-\mathrm{ADH}_{\mathrm{mut}}\right)$, which was designed by Codexis to accept bulkybulky substrates. ${ }^{23,24}$ The enzyme was cloned and over-expressed in $E$. coli and used in purified form (see ESI $\dagger$ ). The enzyme showed very good activity on 2a-3a (up to $81 \%$ activity on $20 \mathrm{mM}$ of 2a, entry 17, Table S3, ESI $\dagger$ ), with pronounced regiopreference for $\mathbf{2 b}$, but mixed selectivity on $\mathbf{3 a}$, confirming the general trend of the tested ADHs not able to perform best on both substrates simultaneously, a surprising feature given the high structural similarity between $\mathbf{2 a}$ and $\mathbf{3 a}$.

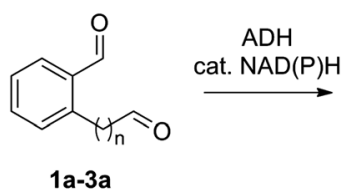

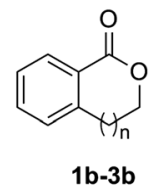<smiles>O=C1COCc2ccccc2N1</smiles>
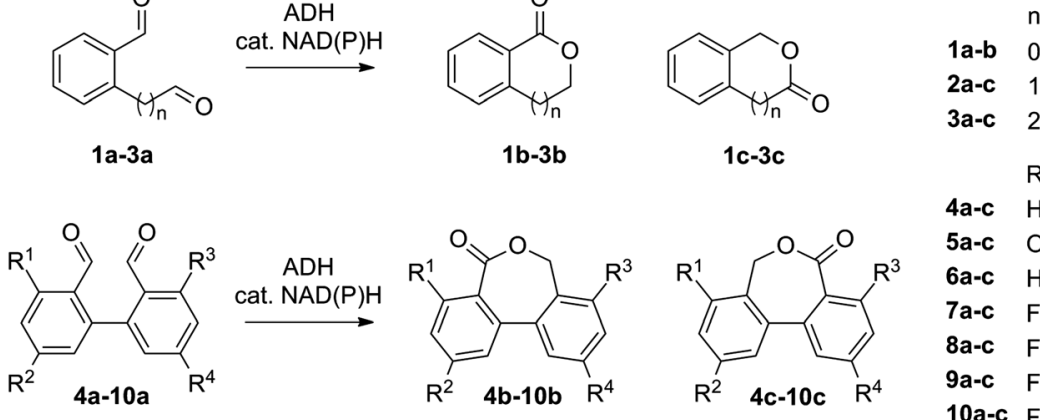

$\begin{array}{lllll} & \mathrm{R}^{1} & \mathrm{R}^{2} & \mathrm{R}^{3} & \mathrm{R}^{4} \\ \text { 4a-c } & \mathrm{H} & \mathrm{H} & \mathrm{H} & \mathrm{H} \\ \text { 5a-c } & \mathrm{OMe} & \mathrm{H} & \mathrm{H} & \mathrm{H} \\ \text { 6a-c } & \mathrm{H} & \mathrm{OMe} & \mathrm{H} & \mathrm{H} \\ \text { 7a-c } & \mathrm{F} & \mathrm{H} & \mathrm{H} & \mathrm{H} \\ \text { 8a-c } & \mathrm{F} & \mathrm{H} & \mathrm{OMe} \mathrm{H} \\ \text { 9a-c } & \mathrm{F} & \mathrm{H} & \mathrm{H} & \mathrm{OMe} \\ \text { 10a-c } & \mathrm{F} & \mathrm{H} & \mathrm{F} & \mathrm{H}\end{array}$

Scheme 2 Conversion of $\mathbf{1 a - 1 0 a}$ into two possible regioisomers $\mathbf{1 b}-\mathbf{1 0 b}$ and $\mathbf{1 c}-\mathbf{1 0} \mathbf{c}$ in the intramolecular Tishchenko-like reaction catalyzed by alcohol dehydrogenase (ADH). The cofactor $\mathrm{NAD}(\mathrm{P}) \mathrm{H}$ is added in catalytic amounts. 
Table 1 Conversion of $4 a-10 a$ by best performing $\mathrm{ADH}^{\mathrm{a}}$

\begin{tabular}{llllll}
\hline Entry & Substrate & ADH & Conv. (\%) & $\begin{array}{l}\text { Ratio } \\
\mathbf{4 - 1 0 b} / \mathbf{4 - 1 0 c}\end{array}$ & $\begin{array}{l}\text { Isolated } \\
\text { yield }^{b}(\%)\end{array}$ \\
\hline 1 & $\mathbf{4 a}$ & Lk-ADH $_{\text {mut }}$ & 84 & n.a. & $48^{c}$ \\
2 & $\mathbf{5 a}$ & $132^{d}$ & 96 & $>99: 1$ & $29(\mathbf{5 b})$ \\
3 & $\mathbf{6 a}$ & Lk-ADH $_{\text {mut }}$ & 75 & $97: 3$ & $66(\mathbf{6 b})$ \\
4 & 7a & Lk-ADH $_{\text {mut }}$ & 98 & $14: 86$ & $74(\mathbf{7 c})$ \\
5 & $\mathbf{8 a}$ & 132 & 57 & $1:>99$ & $28(\mathbf{8 c})$ \\
6 & $\mathbf{9 a}$ & 118 & 52 & $1:>99$ & $58^{e}(\mathbf{9 c})$ \\
7 & $\mathbf{1 0 a}$ & $107 / 132$ & $>99$ & n.a. & $56^{e}$
\end{tabular}

a $10 \mathrm{mM}$ of $4 \mathrm{a}-10 \mathrm{a}, 1 \mathrm{mg} \mathrm{mL}{ }^{-1} \mathrm{ADH}, \mathrm{KPi}$ buffer $(50 \mathrm{mM}, \mathrm{pH} 7.0,2 \mathrm{mM}$ $\mathrm{MgCl}_{2}$ ), 5 vol $\% \mathrm{CH}_{3} \mathrm{CN}, 30{ }^{\circ} \mathrm{C}, 500 \mu \mathrm{L}$ volume, $120 \mathrm{rpm} .{ }^{b} 0.1-0.41 \mathrm{mmol}$ scale. ${ }^{c}$ One-pot two-step sequence from bromoaldehyde and 2-formylphenylboronic acid. ${ }^{d} 3 \mathrm{mg} \mathrm{mL}{ }^{-1} \mathrm{ADH}, 1 \mathrm{mM}$ NADH. ${ }^{e} \mathrm{Lk}^{2} \mathrm{ADH}_{\mathrm{mut}}$ employed due to better availability of the enzyme preparation.

Next, a range of variously substituted $\left[1,1^{\prime}\right.$-biphenyl $]-2,2^{\prime}$ dicarbaldehyde substrates 4a-10a obtained by Pd-catalyzed SuzukiMiyaura coupling reaction ${ }^{25}$ was studied, aiming at the synthesis of dibenzo[c,e]oxepin-5(7H)-ones. Good to excellent conversion levels were obtained with non-substituted $\mathbf{4 a}$, with $\mathrm{Lk}^{-\mathrm{ADH}_{\text {mut }}}$ performing the best (82-90\% conversion on $5-15 \mathrm{mM} 4 \mathbf{4 a}$, entry 1 , Table 1 , and see ESI, $\uparrow$ Table S4). Inspired by previous reports demonstrating the compatibility of $\mathrm{ADH}$ with Pd-catalyst, ${ }^{26}$ we designed an aqueous chemoenzymatic one-pot two-step cascade for the synthesis of $\mathbf{4 b}$ on $50 \mathrm{mg}$ scale (Scheme 3). The Pd-catalyzed cross-coupling reaction proceeded in water at $90{ }^{\circ} \mathrm{C}$ with 3 eq. of $\mathrm{Na}_{2} \mathrm{CO}_{3}$, and was followed - upon dilution to $15 \mathrm{mM} 4 \mathrm{4a}$ with buffer and 5 vol\% acetonitrile and $\mathrm{pH}$ adjustment - by the $\mathrm{ADH}$-catalyzed reaction

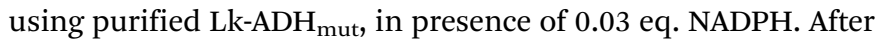
purification by flash chromatography, dibenzo[c,e]oxepin-5(7H)one ( $4 \mathbf{b})$ could be obtained in $48 \%$ isolated yield (entry 1 , Table 1 ).

During further study of the enzymatic reaction, the electronic properties of the substituents were found to have a major effect on the conversion levels of 5a-10a. Overall, the electron-withdrawing group (EWG, -F) strongly favored activity, as most enzymes showed good to excellent activity on $7 \mathbf{a}$ (up to $98 \%$ conversion, entry 4 , Table 1), while the effect of the electron-donating group (EDG, -OMe) was opposite and most enzymes were poorly active or not active on 5a-6a (see ESI, $\uparrow$ Table S5). With 5a-6a, ADH-132 showed promising conversion, which could be boosted on $\mathbf{5 a}$ by providing more enzyme and cofactor (entry 2, Table 1). $\mathrm{Lk}^{-\mathrm{ADH}_{\text {mut }} \text { was found }}$ very active on $\mathbf{6 a}$ (entry 3 , Table 1), however, conversion of $\mathbf{5 a}$ was very poor (5\%, see ESI, $\dagger$ Table S5). More striking was the degree of regioselectivity observed with all enzymes, which preferentially delivered one regioisomer. Regardless of the biocatalyst, the EWG was always found on the ring bearing the aldehyde that got reduced first, leading to the formation of 8 -fluorodibenzo $[c, e]$ oxepin$5(7 \mathrm{H})$-one (7c), while the EDG was found on the ring bearing the aldehyde that remained inert in the first reductive step, leading to the formation of 4- and 2-methoxydibenzo[c,e]oxepin-5(7H)-ones (5b and $\mathbf{6 b}$ ). Clearly, the EWG increased the electrophilicity of the aldehyde group and thereby favored attack by the hydride, while the EDG favored attack of the aldehyde group located on the opposite ring (Scheme S2, ESI $\dagger$ ). The regiopreference was exquisite on $\mathbf{5 a}$ (no trace of $\mathbf{5} \mathbf{c}$ detected) and led to predominant formation of regioisomers $\mathbf{6 b}$ and $\mathbf{7} \mathbf{c}$ with $\mathbf{6 a}$ and $7 \mathbf{a}$, respectively (up to $97: 3$ ratio for $\mathbf{6 b} / \mathbf{6 c}$ in $75 \%$ conversion and $5: 95$ ratio for $7 \mathbf{b} / 7 \mathbf{c}$ in $15 \%$ conversion, respectively, see ESI, $\dagger$ Table S5). These effects were confirmed by adding a substituent on the second ring. Conversion of 10a was increased in most cases compared to conversion of 7a (up to full conversion, see ESI, $\dagger$ Tables S6, S7 and entry 7, Table 1), confirming that EWGs are facilitating the reaction. Addition of an EWG on poorly reactive 5a-6a turned beneficial in selected cases and led to significant increase in conversion level of 8a with some biocatalysts (up to $400 \%$ increase in conversion compared to $\mathbf{5 a}$ ), while the effect was much less encouraging on 9a (see ESI, $\dagger$ Tables S6 and S7); with the latter, most dramatic change was seen in the regioselectivity, as all ADHs delivered only regioisomer 9c, which can hint as a 'cumulative' effect of the electronic properties on the regioselectivity (see ESI, $\uparrow$ Table S6 and Scheme S2). Finally, these substrates were subjected to preparative synthesis on up to $100 \mathrm{mg}$ scale and corresponding dibenzo[c,e]oxepin-5(7H)-ones $\mathbf{4 b - 6 b}$ and $\mathbf{7} \mathbf{c}-\mathbf{1 0 c}$ could be obtained after purification by flash chromatography in very good isolated yield (up to 74\%, Table 1) and excellent purity (see ESI $\dagger$ ).

In order to analyze the hydride economy and the overall catalytic performance of the system, use of isolated and purified $\mathrm{ADH}$ was necessary. To that end, and given the high conversion level achieved with 0.05 eq. NADPH and $1 \mathrm{mg} \mathrm{mL}{ }^{-1} \mathrm{ADH}$ ( $\sim 37 \mu \mathrm{M}, 0.37 \mathrm{~mol} \%)$, the transformation of $7 \mathbf{a}$ by $\mathrm{Lk}^{-\mathrm{ADH}_{\mathrm{mut}}}$ was closely looked at (Table 2). Cofactor and enzyme concentrations were varied and the resulting data indicate that (i) the catalyst was highly active and conversion up to $77 \%$ could be achieved using only $3.7 \mu \mathrm{M}(0.037 \mathrm{~mol} \%)$ of $\mathrm{ADH}$, which corresponds to a total turnover number (TTN) of 2081 (entry 5, Table 2); (ii) the hydride economy was excellent: turnover number (TON) up to 880 was achieved with 0.001 eq. of NADPH, translating in $1.6 \times 10^{3}$ halfreactions per mole of cofactor (entry 2, Table 2). This cofactor loading is one of the lowest reported for NAD(P)-dependent selfsufficient biocatalytic systems yielding such high conversion levels. ${ }^{16}$ In biotransformations (one substrate $\rightarrow$ one product) using a combination of enzymes, max. 470 TON has been

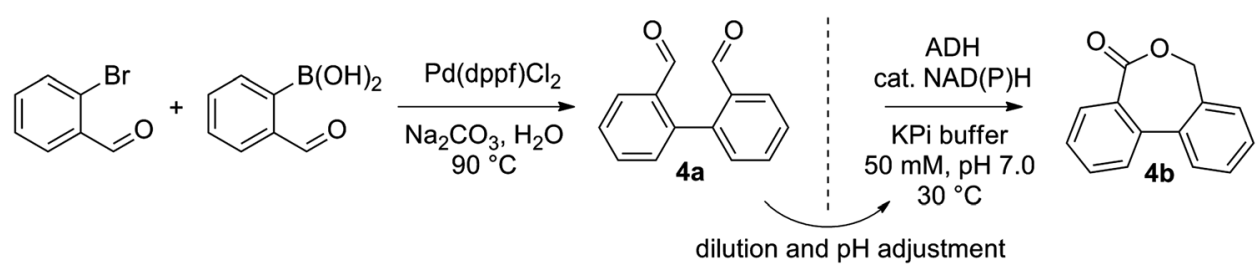

Scheme 3 Aqueous sequential chemoenzymatic one-pot cascade of Suzuki-Miyaura coupling and ADH-catalyzed lactonization. 
Table 2 Conversion of $7 \mathrm{a}(10 \mathrm{mM})$ by $\mathrm{Lk}^{-A D H} \mathrm{H}_{\text {mut }}$ (standard conditions)

\begin{tabular}{llllcc}
\hline Entry & {$[\mathrm{ADH}](\mu \mathrm{M})$} & {$[\mathrm{NADPH}]($ eq. $)$} & Conv. $^{a}(\%)$ & TON $_{\mathrm{NADPH}}$ & TTN $_{\mathrm{ADH}}{ }^{b}$ \\
\hline 1 & 37 & 0.05 & 98 & 19.6 & 265 \\
2 & 37 & 0.001 & 88 & 880 & 238 \\
3 & 18.5 & 0.025 & 89 & 35.6 & 481 \\
4 & 18.5 & 0.001 & 82 & 820 & 443 \\
5 & 3.7 & 0.025 & 77 & 30.8 & 2081 \\
6 & 3.7 & 0.001 & 64 & 640 & 1729
\end{tabular}

${ }^{a}$ Ratio $7 \mathbf{b} / 7 \mathbf{c} 14: 86 .{ }^{b}$ Two half-reactions per TTN.

reported $(0.002 \text { eq. of } \mathrm{NADPH})^{27}$ but typical TON values are $<100 .^{16}$ Compared to reported protocols relying on a single ADH (TON 10-30), ${ }^{11,19,20}$ the bio-Tischenko-like reaction stands out due to highly effective internal hydride shuffling, likely due to the thermodynamic advantage provided by the spontaneous cyclization of the hydroxyaldehyde.

Collectively, the data demonstrate that formal intramolecular 1,4-, 1,5- and 1,6-hydride shift on dialdehydes can be catalyzed by nicotinamide-dependent alcohol dehydrogenases. The resulting bioTishchenko-like reaction provides access to lactones in a redoxneutral manner through a simple protocol under mild conditions in aqueous environment (max. 5 vol\% organic co-solvent). By investigating a panel of $\mathrm{ADHs}$, regioselective formation of isochroman-1one and 4,5-dihydrobenzo[c]oxepin-1(3H)-one could be achieved. With substituted [1,1'-biphenyl]-2,2'-dicarbaldehydes, regiocomplementarity could be induced by varying the electronic properties of the substituent. This strategy was successfully applied to the regioselective synthesis of 2-, 4- and 8-substituted dibenzo[c,e]oxepin$5(7 H)$-ones. Importantly, this self-sufficient biocatalytic system displays excellent hydride economy. Combination of the enzymatic step with Pd-catalyzed cross-coupling in one pot finally provides an elegant chemoenzymatic cascade applicable to the synthesis of lactones.

Funding by the Austrian Science Fund is gratefully acknowledged (P30519-N36). We thank Prof. K. Zangger and B. Werner for NMR measurements, P. M. Neu for HRMS analyses, A. Billiani and L. Schober for technical assistance, and J. Schrittwieser and M. Fuchs for fruitful scientific discussions.

\section{Conflicts of interest}

There are no conflicts to declare.

\section{References}

1 S. A. Morris and D. G. Gusev, Angew. Chem., Int. Ed., 2017, 56, 6228. 2 T. Seki, T. Nakajo and M. Onaka, Chem. Lett., 2006, 35, 824.

3 M. Nielsen, H. Junge, A. Kammer and M. Beller, Angew. Chem., Int. Ed., 2012, 51, 5711.

4 (a) S. H. Bergens, D. P. Fairlie and B. Bosnich, Organometallics, 1990, 9, 566; (b) M. R. Burgstein, H. Berberich and P. W. Roesky, Chem. Eur. J., 2001, 7, 3078; (c) S. Onozawa, T. Sakakura, M. Tanaka and
M. Shiro, Tetrahedron, 1996, 52, 4291; (d) T. Ooi, T. Miura, K. Takaya and K. Maruoka, Tetrahedron Lett., 1999, 40, 7695.

5 J. Uenishi, S. Masuda and S. Wakabayashi, Tetrahedron Lett., 1991, 32, 5097.

6 T. Ooi, T. Miura, Y. Itagaki, I. Ichikawa and K. Maruoka, Synthesis, 2002, 279.

7 (a) M. G. Edwards and J. M. J. Williams, Angew. Chem., Int. Ed., 2002, 41, 4740; (b) A. Labonne, L. Zani, L. Hintermann and C. Bolm, J. Org. Chem., 2007, 72, 5704; (c) M. C. Haibach and D. Seidel, Angew. Chem., Int. Ed., 2014, 53, 5010.

8 M. H. S. A. Hamid, P. A. Slatford and J. M. J. Williams, Adv. Synth. Catal., 2007, 349, 1555.

9 (a) J. L. Hsu and J. M. Fang, J. Org. Chem., 2001, 66, 8573; (b) S. Omura, T. Fukuyama, Y. Murakami, H. Okamoto and I. Ryu, Chem. Commun., 2009, 6741; (c) Z. M. Shen, P. K. Dornan, H. A. Khan, T. K. Woo and V. M. Dong, J. Am. Chem. Soc., 2009, 131, 1077; (d) Z. M. Shen, H. A. Khan and V. M. Dong, J. Am. Chem. Soc., 2008, 130, 2916; (e) T. Suzuki, T. Yamada, K. Watanabe and T. Katoh, Bioorg. Med. Chem. Lett., 2005, 15, 2583.

10 Y. Noma, Y. Okajima, H. Takahashi and Y. Asakawa, Phytochemistry, 1991, 30, 2969.

11 E. Tassano, K. Faber and M. Hall, Adv. Synth. Catal., 2018, 360, 2742.

12 C. Wuensch, H. Lechner, S. M. Glueck, K. Zangger, M. Hall and K. Faber, ChemCatChem, 2013, 5, 1744.

13 A. J. Irwin and J. B. Jones, J. Am. Chem. Soc., 1977, 99, 1625.

14 (a) A. J. Irwin and J. B. Jones, J. Am. Chem. Soc., 1977, 99, 556; (b) I. J. Jakovac, H. B. Goodbrand, K. P. Lok and J. B. Jones, J. Am. Chem. Soc., 1982, 104, 4659; (c) J. B. Jones and C. J. Francis, Can. J. Chem./Rev. Can. Chim., 1984, 62, 2578.

15 (a) G. Hilt, B. Lewall, G. Montero, J. H. P. Utley and E. Steckhan, Liebigs Ann./Recueil, 1997, 2289; (b) I. Schroder, E. Steckhan and A. Liese, J. Electroanal. Chem., 2003, 541, 109.

16 E. Tassano and M. Hall, Chem. Soc. Rev., 2019, 48, 5596.

17 (a) S. Gargiulo, D. J. Opperman, U. Hanefeld, I. W. C. E. Arends and F. Hollmann, Chem. Commun., 2012, 48, 6630; (b) S. Kara, D. Spickermann, J. H. Schrittwieser, C. Leggewie, W. J. H. van Berkel, I. W. C. E. Arends and F. Hollmann, Green Chem., 2013, 15, 330; (c) S. Kara, D. Spickermann, J. H. Schrittwieser, A. Weckbecker, C. Leggewie, I. W. C. E. Arends and F. Hollmann, ACS Catal., 2013, 3, 2436; (d) R. Zuhse, C. Leggewie, F. Hollmann and S. Kara, Org. Process Res. Dev., 2015, 19, 369.

18 (a) A. Diaz-Rodriguez, L. Martinez-Montero, I. Lavandera, V. Gotor and V. Gotor-Fernandez, Adv. Synth. Catal., 2014, 356, 2321; (b) A. Diaz-Rodriguez, I. Lavandera, S. Kanbak-Aksu, R. A. Sheldon, V. Gotor and V. Gotor-Fernandez, Adv. Synth. Catal., 2012, 354, 3405.

19 C. C. Gruber, B. M. Nestl, J. Gross, P. Hildebrandt, U. T. Bornscheuer, K. Faber and W. Kroutil, Chem. - Eur. J., 2007, 13, 8271.

20 Y. C. Liu, C. Merten and J. Deska, Angew. Chem., Int. Ed., 2018, $57,12151$.

21 R. Schmiedel, A. Vogel, S. Köpke, R. Czaja, C. Feller, H. Merkens, K. Rzeznicka, A. Petri, D. Schwarze, M. Struhalla and T. GreinerStöffele, WO 2015/162064 A1, 2015.

22 A. Rioz-Martinez, G. de Gonzalo, D. E. T. Pazmino, M. W. Fraaije and V. Gotor, Eur. J. Org. Chem., 2009, 2526.

23 N. K. Modukuru, J. Sukumaran, S. J. Collier, A. S. Chan, A. Gohel, G. W. Huisman, R. Keledjian, K. Narayanaswamy, S. J. Novick, S. M. Palanivel, D. Smith, Z. Wei, B. Wong, W. L. Yeo and D. A. Entwistle, Org. Process Res. Dev., 2014, 18, 810.

24 A. Gohel, D. J. Smith, B. Wong, J. Sukumaran, W. L. Yeo, S. J. Collier and S. Novick, US Pat., US20140199735, 2014.

25 N. Miyaura and A. Suzuki, Chem. Rev., 1995, 95, 2457.

26 (a) E. Burda, W. Hummel and H. Groger, Angew. Chem., Int. Ed., 2008, 47, 9551; (b) D. Gonzalez-Martinez, V. Gotor and V. GotorFernandez, ChemCatChem, 2019, 11, 5800.

27 T. Knaus, F. G. Mutti, L. D. Humphreys, N. J. Turner and N. S. Scrutton, Org. Biomol. Chem., 2015, 13, 223. 